\title{
EFFECT OF COMPOSITION OF BARRIER LAYERS REGION ON POLARIZATION RADIATION CHARACTERISTICS OF QUANTUM-WELL HETEROLASER
}

\author{
A.G. Buikevich and I.S. Manak \\ Belarusian State University, F. Skaryna Ave 4, Minsk, 220050, Belarus \\ E-mail: buikevich@bsu.by
}

Received 30 March 2005

\begin{abstract}
Effect of componental composition of quantum-well heterostructures' barrier waveguide layers in $\mathrm{GaAs}-\mathrm{Al}_{x} \mathrm{Ga}_{1-x} \mathrm{As}$ system on the polarization degree of spontaneous and stimulated radiations is investigated. It is shown, that given $x$ at frequencies near the basic optical transitions, a spontaneous radiation polarization degree sign change occurs. In the oscillating mode, depending on a waveguide layer componental composition, the generation of the entirely polarized radiation of TE- or TM-type is possible.
\end{abstract}

Keywords: quantum-well heterolaser, polarization of radiation, gain, TE- and TM-modes

PACS: $78.45 .+\mathrm{h}, 73.21 . \mathrm{Fg}$, 42.25.Ja

\section{Introduction}

Quantum-well injection lasers have an essential advantage against traditional laser diodes due to the improved lasing characteristics that allow the lasers of this type to be widely applied in various fields of science and technology. Polarization properties of amplification spectra of this type of lasers are connected with the dependence of probability of optical transitions to the heavy and light electron hole states on the type of mode [1], orientation, geometry, and size of lasing regions [2-4]. The analysis of influence of componental content variations of quantum-well heterostructure layers on light polarization characteristics has a doubtless interest as regards the optimization of light output characteristics and the making of laser diodes with required polarization type.

\section{Theory}

The major influence on spectral characteristics of quantum well radiation have the states of initial levels of electron $E_{c n}$ and electron hole $E_{v i n}$ subbands which are found from expressions [5]

$$
E_{c n}=\frac{E_{c n}^{\infty}}{n^{2}}\left(n-\frac{2}{\pi} \operatorname{arccot} \sqrt{\frac{m_{c}}{m_{c b}}} \sqrt{\frac{E_{c b}}{E_{c n}}}-1\right)^{2},
$$

$$
E_{v i n}=\frac{E_{v i n}^{\infty}}{n^{2}}\left(n-\frac{2}{\pi} \operatorname{arccot} \sqrt{\frac{m_{v i l}}{m_{v i l b}}} \sqrt{\frac{E_{v b}}{E_{v i n}}}-1\right)^{2},
$$

where $\quad E_{c n}^{\infty}=\pi^{2} \hbar^{2} n^{2} /\left(2 m_{c} d^{2}\right) \quad$ and $\quad E_{\text {vin }}^{\infty}=$ $\pi^{2} \hbar^{2} n^{2} /\left(2 m_{\text {vil }} d^{2}\right)$ are the electron and hole subband level values calculated in the infinite barrier approach, $m_{c}$ and $m_{c b}$ are effective masses of the electrons in active region and barrier layers accordingly, $m_{v i l}$ and $m_{\text {vilb }}$ are longitudinal components of hole effective masses in the active and waveguide layers, $i=h, l$ is an index designating heavy and light holes, respectively, $E_{c b}$ and $E_{v b}$ are the potential barrier heights in the quantum well, $n=1,2,3, \ldots$ is a quantum number.

For the considered quantum-well heterostructure in the $\mathrm{Al}_{x} \mathrm{Ga}_{1-x} \mathrm{As} / \mathrm{GaAs}$ system the height of potential barrier practically linearly depends on aluminium molar concentration $x$ [5]. At the point $\Gamma$ of the Brillouin band the band-gap width $E_{g}$ depends on $x$ at $T=300 \mathrm{~K}$ as $E_{g}=\left(1.424+1.155 x+0.37 x^{2}\right) \mathrm{eV}$, and the potential barrier heights in the conduction and valence bands are $E_{c b}=0.848 x, E_{v b}=0.399 x \mathrm{eV}$, respectively. Effective mass of the electron at the bottom of the conduction band depends on $x$ as $m_{c}=$ $(0.067+0.083 x) m_{e}$. For the holes, besides division into light and heavy ones, it is necessary to take into account the mass anisotropy.

The level position of the hole subbands in the quantum well is determined by longitudinal component of 
the effective mass. For the heavy holes the value of longitudinal effective mass depends on $x$ as $m_{v h l}=$ $(0.34+0.42 x) m_{e}$, and for the light holes - as $m_{v l l}=$ $(0.094+0.043 x) m_{e}$.

Laser radiation is known to be the combination of spontaneous and stimulated radiations. The intensity of spontaneous radiation is specified by the velocity of spontaneous transitions $[6,7]$ :

$$
\begin{gathered}
r_{\mathrm{sp}}^{\gamma}(h \nu)=\frac{A_{c v}}{\pi \hbar^{2} d} \sum_{n} \sum_{i} m_{r i t} \\
\times \int f_{e}\left(E_{c n i}\right) f_{h}\left(E_{v n i}\right) L\left(h \nu-E_{c v}\right) \alpha_{n i}^{\gamma} \mathrm{d} E_{c v},
\end{gathered}
$$

where $A_{c v}$ is Einstein coefficient, $d$ is the width of the quantum well, $m_{\text {rit }}=m_{c} m_{\text {vit }} /\left(m_{c}+m_{\text {vit }}\right)$ is the reduced mass associated with the respective transversal components of the heavy or light holes $(i=h, l)$, parameter $\alpha_{n i}^{\gamma}$ characterizes polarization dependence of the probability of the optical transitions and depends on the type of modes (TE or TM), levels involved (heavy or light holes), and transition energy $E_{c v}=E_{c n i}-E_{v n i}$ [6]; $f_{e}\left(E_{c n i}\right)$ and $f_{h}\left(E_{v n i}\right)$ are Fermi-Dirac distribution functions of the electrons and holes of the states $E_{c n i}$ and $E_{v n i}$ participating in the optical transitions [8]:

$$
\begin{aligned}
& E_{c n i}=E_{c 0}+E_{c n}+\frac{m_{r i t}}{m_{c}}\left(E_{c v}-h \nu_{n i}\right), \\
& E_{v n i}=E_{v 0}-E_{v i n}-\frac{m_{r i t}}{m_{v i t}}\left(E_{c v}-h \nu_{n i}\right) .
\end{aligned}
$$

$E_{c 0}$ and $E_{v 0}$ are the energies of the bottom of conduction band and the top of valence band, respectively, $E_{c n}$ and $E_{v i n}$ are the ground levels of subbands with number $n$ for the electrons and heavy or light holes, $h \nu_{n i}=E_{g}+E_{c n}+E_{v i n}$ is the energy of initial optical transitions with a participation of these states, $\Delta F=F_{e}-F_{h}$ is difference of the quasi-Fermi levels, $T$ is temperature. Function $L\left(h \nu-E_{c v}\right)$, which takes into account the broadening of spectral lines in semiconductor lasers, is approximated by a Lorentzian

$$
L\left(h \nu-E_{c v}\right)=\frac{1}{\pi} \frac{\Gamma_{c v}}{\left(h \nu-E_{c v}\right)^{2}+\Gamma_{c v}^{2}} .
$$

Equations (1-4) are also supplemented with the requirement of electroneutrality of active region [7].

The degree of radiation polarization is given by the formula

$$
P=\frac{I^{\mathrm{TE}}-I^{\mathrm{TM}}}{I^{\mathrm{TE}}+I^{\mathrm{TM}}}
$$

where $I^{\mathrm{TE}}$ and $I^{\mathrm{TM}}$ are intensities of the corresponding polarization radiation; in case of spontaneous radiation $I^{\gamma} \sim r_{\mathrm{sp}}^{\gamma}$.

The radiation intensity of the quantum-well laser with nonselective resonator in the oscillation mode can be calculated using the rate equations [8]

$$
\begin{gathered}
\frac{\mathrm{d} N}{\mathrm{~d} t}=\frac{j}{e d}-R_{\mathrm{sp}}-\sum_{\gamma} \sum_{m} \nu \Gamma^{\gamma} k_{m}^{\gamma} S_{m}^{\gamma}, \\
\frac{\mathrm{d} S_{m}^{\gamma}}{\mathrm{d} t}=\nu\left(\Gamma^{\gamma} k_{m}^{\gamma}-k_{1}^{\gamma}\right) S_{m}^{\gamma}+\beta R_{\mathrm{sp}},
\end{gathered}
$$

where $N$ is concentration of nonequilibrium carriers in the active region, $S_{m}^{\gamma}$ is a photon density, $j$ is pump current density, $R_{\mathrm{sp}}=\int r_{\mathrm{sp}}(h \nu) \mathrm{d}(h \nu)$ is rate of spontaneous recombination, $k_{1}^{\gamma}$ is loss coefficient, $\Gamma^{\gamma}$ is optical confinement factor, $\beta$ is coefficient showing the contribution of spontaneous emission transitions to the laser mode, $\gamma=\mathrm{TE}, \mathrm{TM}$ is mode polarization index, $m$ is longitudinal mode number, and the expression for gain factor $k_{m}^{\gamma}(\nu)$ is given by

$$
\begin{aligned}
& k_{m}^{\gamma}=k_{0} \sum_{n} \sum_{i} \frac{m_{r i t}}{m_{e}} \int\left[1-\exp \left(\frac{E_{c v}-\Delta F}{k T}\right)\right] \\
& \times f_{e}\left(E_{c n i}\right) f_{h}\left(E_{v n i}\right) L\left(h \nu_{m}-E_{c v}\right) \alpha_{n i}^{\gamma}\left(E_{c v}\right) \mathrm{d} E_{c v},
\end{aligned}
$$

where $k_{0}=A_{c v} m_{e} /\left(\pi \hbar^{2} v \rho d\right)=8.0 \cdot 10^{4} \mathrm{~cm}^{-1}, \rho$ is density of the electromagnetic modes. The stationary combined equations (6) $\left(\mathrm{d} N / \mathrm{d} t=0, \mathrm{~d} S^{\gamma} / \mathrm{d} t=0\right)$ are supplemented with the equation for the optical confinement factor $\Gamma^{\gamma}$ [8].

The intensity of the mode with order number $m$ is supposed to be

$$
I_{m}^{\gamma}=h \nu_{m} v S_{m}^{\gamma} .
$$

Calculations were carried out with the following values of parameters: $d=8 \mathrm{~nm}, v=c / n_{a}, n_{a}=3.6$, $\Gamma^{\mathrm{TE}}=2.29 \cdot 10^{-2}, \Gamma^{\mathrm{TM}}=1.80 \cdot 10^{-2}$ at $\lambda=825 \mathrm{~nm}$, $k_{1}^{\mathrm{TE}}=30 \mathrm{~cm}^{-1}, k_{1}^{\mathrm{TM}}=25 \mathrm{~cm}^{-1}, \beta=10^{-4}$, $\Gamma_{c v}=10 \mathrm{meV}, T=300 \mathrm{~K}$.

Figure 1 shows dependences of the spontaneous radiation polarization degree on (a) energy of emited quantum $h \nu$ and (b) quasi-Fermi level difference $\Delta F$. As can be seen, the increase of aluminium molar concentration $x$ in the barrier waveguide layers leads to a shift of a graphic chart of the polarization degree $P$ to the short-wave area. This fact can be explained by the shift of the initial subband levels of electrons and holes to the high-energy area as $x$ increases. It is of particular interest when the polarization degree changes a sign 


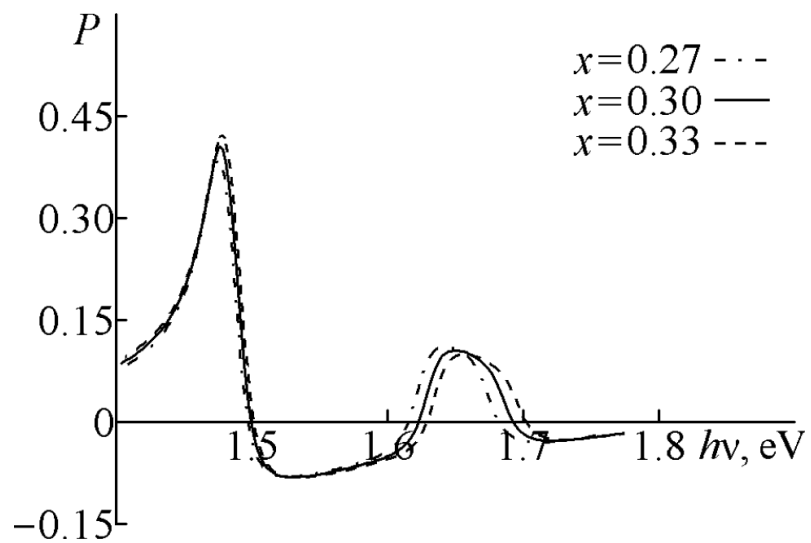

(a)

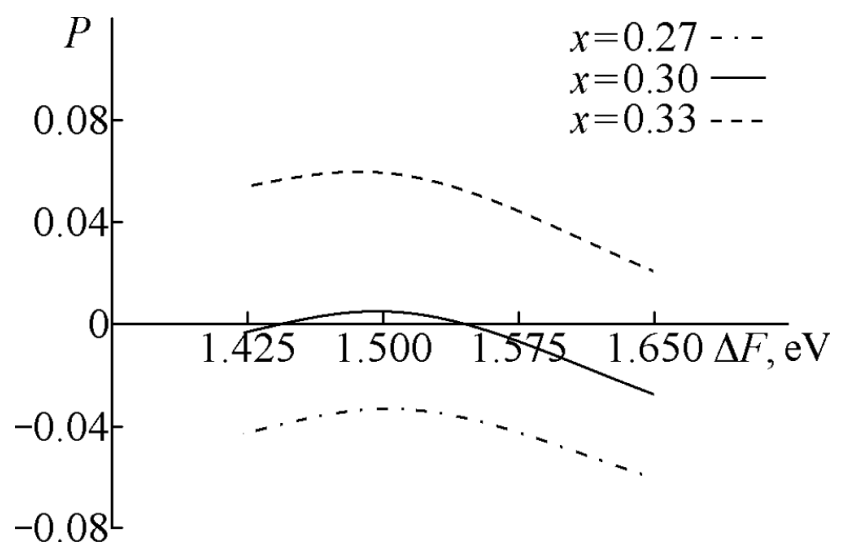

(b)

Fig. 1. Dependence of spontaneous radiation polarization degree $P$ on (a) quantum energy $h \nu$ (at $\Delta F=1.555 \mathrm{eV}$ ) and (b) quasi-Fermi level difference $\Delta F$ (at $h \nu=1.4797 \mathrm{eV}, \lambda=828.2 \mathrm{~nm}$ ).

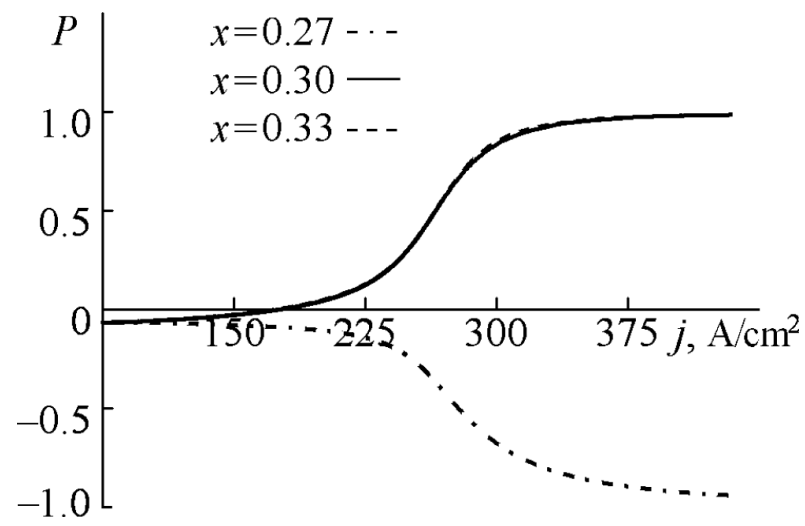

Fig. 2. Dependence of the polarization degree $P$ on the pump current density $j$ at various values of $x$.

at frequencies close to the initial optical transitions depending on the given value of $x$ (Fig. 1(b)).

In Fig. 2 the dependences of the degree of radiation polarization $P$ on the pump current density $j$ are presented. As it was mentioned above, as $x$ increases, the shift of the electron and hole subband levels to the high-energy area takes place and as a result the oscillation wave length moves to the short-wave area. Given the loss level, when $x$ is crossing the value of 0.27 , a change of the polarization from TM- to TE-type takes place. Besides, a shift of the electron and hole subband levels to the high-energy area leads to a decrease of the density of states in a quantum well, thus the threshold current density increases with $x$, too (Fig. 3).

\section{Conclusions}

On the basis of numerical modelling of polarization degree of spontaneous and stimulated radiation of quantum-well heterostructure, it is possible to make the following conclusions. The change of polarization de-

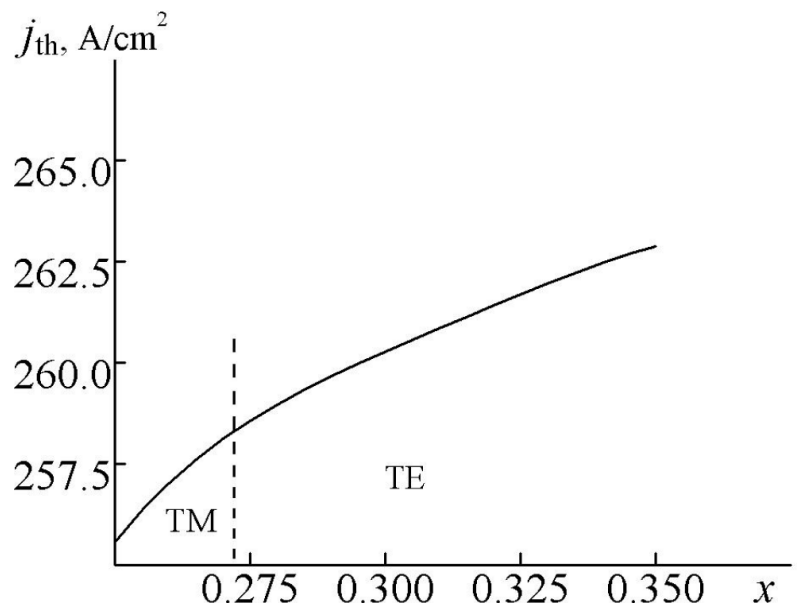

Fig. 3. Dependence of the threshold current density $j_{\text {th }}$ on $x$.

gree of spontaneous radiation $P$, depending on an energy of the emitted quantum $h \nu$ at switching of emission transitions between heavy and light hole subbands, occurs step-wisely. Variations of the composition of barrier layers of heterostructure qualitatively do not influence the polarisation of spontaneous radiation. In an oscillating mode, by varying the molar fraction of aluminium in barrier layers of quantum-well heterostructures, semiconducting laser emiters with the specified polarisation type (TE or TM) at an optimum value of the generation threshold can be obtained.

\section{References}

[1] M. Yamanishi and I. Suemune, Comment on polarisation dependent momentum matrix elements in quantum well lasers, Jpn. J. Appl. Phys. 23(1), L35-L36 (1984).

[2] P.C. Sercel and K.J. Vahala, Polarization dependence of optical absorption and emission in quantum wires, Phys. Rev. B 44(11), 5681-5691 (1991). 
[3] T. Tanaka, T. Yamauchi, J.N. Shulman, and Y. Arakawa, Cross sectional shape dependence of quantum wire band structures and optical matrix elements, Jpn. J. Appl. Phys. Pt. 2 32(11A), L1592-L1595 (1993).

[4] A.A. Vitalisov and V.K. Kononenko, Polarization characteristics of quantum wire semiconductor emitters, in: Laser and Optico-Electronic Techniques, Issue 3 (BSU, Minsk, 1995), pp. 34-43 [in Russian].

[5] A.A. Afonenko, V.K. Kononenko, and I.S. Manak, Theory of Semiconductor Lasers (BSU, Minsk, 1995) [in Russian].

[6] V.K. Kononenko, I.S. Manak, S.V. Nalivko, V.A. Shevtsov, and D.S. Shulyaev, Gain and lumi- nescence spectra of broadband emitters based on asymmetric quantum-well heterostructures, J. Appl. Spectrosc. 64(2), 234-241 (1997).

[7] A.G. Buikevich, V.K. Kononenko, K.V. Kurnosov, and I.S. Manak, Polarization degree of quantum-well heterolaser radiation, in: Laser and Optico-Electronic Techniques, Issue 6 (BSU, Minsk, 2001), pp. 68-75 [in Russian].

[8] A.G. Buikevich, V.K. Kononenko, and I.S. Manak, Degree of polarization of radiation from a quantum-well heterolaser with a nonselective resonator, J. Appl. Spectrosc. 71(2), 209-214 (2004).

\title{
BARJERINIŲ SLUOKSNIŲ SRITIES SUDĖTIES ITTAKA KVANTINIŲ DUOBIŲ HETEROLAZERIO SPINDULIUOTĖS POLIARIZACIJOS CHARAKTERISTIKOMS
}

\author{
A.G. Buikevich, I.S. Manak \\ Baltarusijos valstybinis universitetas, Minskas, Baltarusija
}

\section{Santrauka}

Tiriama kvantiniu duobiu heterosandarų barjeru bangolaidiniu sluoksniu komponentinès sudèties įtaka savaiminès ir priverstinès spinduliuotès poliarizacijos laipsniui $\mathrm{GaAs}-\mathrm{Al}_{x} \mathrm{Ga}_{1-x} \mathrm{As}$ sistemoje. Parodoma, kad fiksuotam $x$ dažniu srityje, artimoje op- tiniams šuoliams, ivyksta savaiminės spinduliuotès poliarizacijos laipsnio ženklo pokytis. Priklausomai nuo bangolaidinių sluoksniu komponentinès sudèties, osciliuojančioje modoje yra galima visiškai poliarizuotos TE ar TM tipo spinduliuotès generacija. 